\title{
Flagellin gene variation between clinical and environmental isolates of Burkholderia pseudomallei contrasts with the invariance among clinical isolates
}

\author{
C. WINSTANLEY, B. A. HALES, J. E. CORKILL*, M. J. GALLAGHER* and C. A. HART* \\ Department of Biomedical Sciences, University of Bradford, Bradford, West Yorkshire BD7 1DP and \\ * Department of Medical Microbiology, Royal Liverpool University Hospital, PO Box 147, Liverpool L69 3BX
}

\begin{abstract}
The flagellin gene sequence from a clinical isolate of Burkholderia pseudomallei was used to design oligonucleotide primers for PCR/RFLP analysis of flagellin gene variation among clinical and environmental isolates of $B$. pseudomallei. Genes from four clinical and six environmental isolates were amplified and compared by RFLP. The clinical isolates were indistinguishable, but variation was detected among some of the environmental isolates. Sequence analysis of flagellin gene amplified products demonstrated high levels of conservation amongst the flagellin genes of clinical isolates $(>99 \%$ similarity), compared to the variation observed between the clinical isolates and one of the environmental isolates $(<90 \%$ similarity). Genomic comparisons with pulsed-field gel electrophoresis (PFGE) revealed differences between the relationships inferred by flagellin genotyping and PFGE, suggesting that a combination of molecular methods may be useful for the subtyping of $B$. pseudomallei strains.
\end{abstract}

\section{Introduction}

Burkholderia pseudomallei is the causative agent of melioidosis, an often fatal infection endemic in areas of South East Asia and Australia. It is isolated frequently from soil in regions where the disease occurs and this may be the reservoir for infection in man and other animals. There has been considerable interest in developing adequate typing schemes for B. pseudomallei. Several studies have used ribotyping of isolates from northern Australia [1], Western Australia [2] and Thailand [3, 4]. Ribotype groups can be resolved further by random amplified polymorphic DNA [5] or DNA macrorestriction analysis [6]. Molecular approaches to the diagnosis of melioidosis have been developed by targeting regions of the $16 \mathrm{~S}$ rRNA [7] or $23 \mathrm{~S}$ rRNA [8] genes with labelled probes or polymerase chain reaction (PCR) amplification.

Bacterial flagellin genes have provided highly variable targets for the development of typing methods in several bacterial species [9], including Campylobacter

Received 24 Oct. 1997; accepted 18 Dec. 1997.

Corresponding author: Dr C. Winstanley. spp. [10], Salmonella spp. [11], Helicobacter pylori [12] and Pseudomonas aeruginosa [13]. In a preliminary study, flagellin genes from $B$. cepacia were cloned and sequenced [14], and a high degree of homology was noted between the $B$. cepacia flagellin sequence and a published $B$. pseudomallei flagellin sequence [15]. This homology means that $B$. cepacia flagellin gene sequences can be used as probes to identify $B$. pseudomallei flagellin genes in gene libraries. This paper reports the cloning and sequencing of the flagellin gene from three clinical and one environmental isolate of $B$. pseudomallei, and the development of a PCR-based approach to the study of flagellin gene variation in $B$. pseudomallei.

\section{Materials and methods}

\section{B. pseudomallei strains}

E505 was a clinical isolate from a patient in Preston, Lancashire, who may have acquired the strain during a visit to Goa. Clinical isolates E503, E504, E506 were from melioidosis patients in Malaysia. Environmental isolates E955-E960 were from Thailand and were kindly provided by Dr T. Pitt, Central Public Health Laboratory, 61 Colindale Avenue, London. 


\section{Cloning and sequencing of $B$. pseudomallei flagellin genes}

The flagellin gene from the B. cepacia strain E243 was cloned and sequenced [14]. A cloned PCR product, generated with the sense primer BCl (5'-GTIGCICARCARAAYCTIAAYGG-3') and the antisense primer BCR2 (5'-CCNACSGTCTGRCCCTTCTG-3') and comprising c. $450 \mathrm{bp}$ of the B. cepacia flagellin gene, was cloned into the pTAG vector with the LigATor cloning kit (R\&D Systems Europe Ltd). This 450-bp cloned fragment was labelled with digoxigenin-11-2'dUTP (DIG; Boehringer Mannheim) by PCR amplification in a 50- $\mu 1$ reaction containing 1 unit of Dynazyme (Flowgen), $1 \times$ Dynazyme buffer, $100 \mu \mathrm{M}$ nucleotides (dATP, dCTP, dGTP, dTTP), $60 \mu \mathrm{M}$ DIG and $200 \mathrm{nM}$ of each of two vector-designed primers, LIGA1 (5'-ACGCGTTACGTATCGGAT-3') and LIGA2 (5'-CCTAGGCTCGAGAAGCTT-3'). Amplifications were performed in a MiniCycler (Genetic Research Instrumentation) for 30 cycles consisting of $95^{\circ} \mathrm{C}(1$ $\min ), 50{ }^{\circ} \mathrm{C}(1 \mathrm{~min})$ and $72^{\circ} \mathrm{C}(1.5 \mathrm{~min})$. A gene library of $B$. pseudomallei E503 genomic DNA, isolated as described previously [16], was constructed with the SuperCos 1 cosmid vector (Stratagene) and the conditions recommended by the supplier. Flagellin gene-containing clones were identified by hybridisation with the DIG-labelled probe, with anti-DIG-AP Fab fragments and the chemiluminescent substrate CDPStar as directed in the manufacturer's instruction guide (Boehringer). DNA from a flagellin gene-containing cosmid clone was purified with a Qiagen Midipreparation Kit. A 4-kb Sst I-fragment, containing the flagellin gene, was subcloned into pUC19 and both strands were sequenced by the University of Liverpool DNA Sequencing Service with a number of internal oligonucleotide primers. Flagellin gene amplified products generated from strains E505 and E506 with primers BC6 (N-terminal: 5'-AACAGCCTGCAGCGTATC-3') and BCR12 (C-terminal: 5'-ACAG/ TGTTCGCGGTTTCCTG-3' ${ }^{\prime}$ ) and from strain E956 with primers BC6E (N-terminal: 5'-ACCAACAGCCTGCAGCGTATC-3') and BCR14 (C-terminal: 5'TTATTGCAGGAGCTTCAGCAC- $3^{\prime}$ ) were also cloned with the LigATor kit and sequenced. The sequences obtained for strains E505, E506 and E956 represent most but not all of the flagellin genes. These sequences have been deposited in GenBank and given the accession numbers AF030239 (E503), AF030240 (E505) and AF030241 (E956).

\section{PCR/RFLP analysis of B. pseudomallei flagellin genes}

Cell suspensions of $B$. pseudomallei isolates grown on brain heart infusion (BHI) agar were boiled for $5 \mathrm{~min}$ to generate crude DNA preparations. Boiled suspension $(2.5 \mu 1)$ was used directly in an amplification mixture consisting of 0.5 units of Dynazyme, $1 \times$ Dynazyme buffer, $100 \mu \mathrm{M}$ nucleotides (dATP, dCTP, dGTP, dTTP) and $200 \mathrm{nM}$ of the flagellin gene-specific primers BC6E (sense primer for $\mathrm{N}$-terminal region) and BCR14 (antisense primer of $\mathrm{C}$-terminal region), in a total volume of $25 \mu \mathrm{l}$. Amplifications were performed in a MiniCycler for 30 cycles consisting of $95^{\circ} \mathrm{C}(1 \mathrm{~min})$, $60^{\circ} \mathrm{C}(1 \mathrm{~min})$ and $72^{\circ} \mathrm{C}(1.5 \mathrm{~min})$.

Samples $(5 \mu \mathrm{l})$ of amplified product were digested with the restriction endonucleases Hae III, Msp I, $M b o \mathrm{I}, R s a \mathrm{I}$ and $C f o \mathrm{I}$ under the conditions recommended by the supplier (Life Technologies). These digests and PCR size marker (R\&D Systems; fragment sizes: $50,150,300,500,750,1000,1500,2000 \mathrm{bp}$ ) were then subjected to electrophoresis on MetaPhor agarose $3 \% \mathrm{w} / \mathrm{v}$ gels (Flowgen).

\section{Pulsed-field gel electrophoresis}

Bacterial cells were grown overnight at $37^{\circ} \mathrm{C}$ on blood agar plates, harvested by scraping from plates, washed with and suspended in buffer $(10 \mathrm{~mm}$ Tris, $20 \mathrm{~mm}$ $\mathrm{NaCl}, 50 \mathrm{~mm}$ EDTA, pH 7.2) and mixed with an equal volume of pulsed-field certified agarose (Bio-Rad) $2.0 \% \mathrm{w} / \mathrm{v}$ containing $4 \mu \mathrm{l}$ of lysozyme $(25 \mathrm{mg} / \mathrm{ml})$. The mixture was dispensed into $100-\mu 1$ insert-moulds and allowed to solidify on ice. The plugs were incubated in $1 \mathrm{ml}$ of lysozyme buffer $(10 \mathrm{mM}$ Tris, $50 \mathrm{mM} \mathrm{NaCl}$, sodium deoxycholate $0.2 \% \mathrm{w} / \mathrm{v}$, sodium lauryl sarcosine $0.5 \% \mathrm{w} / \mathrm{v}, \mathrm{pH} 7.2$ ) containing $40 \mu \mathrm{l}$ of lysozyme $(25 \mathrm{mg} / \mathrm{ml})$ for $1 \mathrm{~h}$ at $37^{\circ} \mathrm{C}$. After washing in wash buffer $(20 \mathrm{~mm}$ Tris, $50 \mathrm{~mm}$ EDTA, $\mathrm{pH} 8.0)$ the plugs were placed in $1 \mathrm{ml}$ of proteinase $\mathrm{K}$ buffer $(100 \mathrm{~mm}$ EDTA, sodium deoxycholate $0.2 \% \mathrm{w} / \mathrm{v}$, sodium lauryl sarcosine $1.0 \% \mathrm{w} / \mathrm{v}, \mathrm{pH} 8.0$ ) containing $1 \mathrm{mg}$ of proteinase $\mathrm{K}$ and incubated overnight at $50^{\circ} \mathrm{C}$. The plugs were then washed in $1 \mathrm{ml}$ of wash buffer containing $20 \mu \mathrm{l}$ of $100 \mathrm{~mm}$ phenyl methyl sulphonyl fluoride (PMSF) for $30 \mathrm{~min}$. After four further washes each of $30 \mathrm{~min}$ in wash buffer, the plugs were treated with Spe I (BioRad) 2 units/block in $300 \mu \mathrm{l}$ of restriction enzyme buffer and incubated at $37^{\circ} \mathrm{C}$ for $18 \mathrm{~h}$. Restriction fragments were separated by pulsedfield gel electrophoresis (PFGE) in a CHEF DRII system (Bio-Rad) through pulsed-field certified agarose $1 \% \mathrm{w} / \mathrm{v}$ in $0.5 \times \mathrm{TBE}(1 \times \mathrm{TBE}$ is $0.9 \mathrm{M}$ Tris- $\mathrm{HCl}, 0.9$ $\mathrm{M}$ boric acid, $1.0 \mathrm{mM}$ EDTA). Electrophoresis was performed for $20 \mathrm{~h}$ in $0.5 \times \mathrm{TBE}$ at $14^{\circ} \mathrm{C}$ with initial and final pulse times of $5 \mathrm{~s}$ and $35 \mathrm{~s}$ respectively. Lambda phage concatamers were used as DNA size standards.

\section{Cable pilus typing by PCR}

Highly transmissible pathogenic B. cepacia (ET12 lineage) characteristically have long intertwined cable pili [17]. PCR amplification of cable pilin genes from B. cepacia ET12 and B. pseudomallei chromosomal DNA was performed in standard PCR amplification mixtures with sense (5'-CCAAAGGACTAACCCA-3') and anti-sense (5'-ACGCGATGTCCATCACA-3') primers designed to produce an amplicon of $676 \mathrm{bp}$. An 
initial denaturing step of $94^{\circ} \mathrm{C}$ for $3 \mathrm{~min}$ was followed by 30 cycles of $94^{\circ} \mathrm{C}(1 \mathrm{~min}), 55^{\circ} \mathrm{C}(1 \mathrm{~min})$ and $72^{\circ} \mathrm{C}$ (1 $\mathrm{min}$ ).

\section{Computer analyses}

Nucleotide sequence alignments, determination of amino-acid composition and alignments of predicted flagellin proteins with each other or with other flagellins (retrieved from EMBL, GenBank or SwissProt) were performed with GAP, PILEUP and FASTA from the GCG sequence analysis software package (Genetics Computer Group, University of Wisconsin) [18].

\section{Results}

\section{Flagellin gene sequence comparisons}

The complete flagellin gene sequence obtained from strain E503 was identical in length to the published $B$. pseudomallei flagellin gene sequence (1167 bp) [15] and differed in only two positions (798 and 975) both of which were synonymous substitutions, indicating that the peptide sequences were invariable. Flagellin gene and protein variation is known to be far greater in the central region than in the conserved $\mathrm{N}$ - and $\mathrm{C}$ terminal domains [9]. To assess flagellin sequence variability in $B$. pseudomallei, sequence information from PCR-amplified products representing the flagellin gene central domain of three other strains was obtained. The flagellin gene nucleotide sequences for strains E505 and E506 were 100\% identical over $766 \mathrm{bp}$. The available sequence data for E506/E505 flagellin genes indicated only one base difference when compared with E503 flagellin gene (position 798 on the complete gene sequence) and one base difference when compared with the published B. pseudomallei flagellin gene sequence [15] (position 975).

\section{Flagellin genotyping by $P C R / R F L P$}

PCR amplification was possible with all 10 clinical and environmental isolates of $B$. pseudomallei tested. Restriction digest analysis revealed no detectable variation between the four clinical isolates and the environmental isolates E955, E957 and E958. Environmental isolates E956 and E959 gave different flagellin gene PCR/RFLP patterns from the other isolates with Hae III, MspI, MboI, RsaI and CfoI, but were indistinguishable from each other. Isolate E960 could be distinguished from the clinical isolates with only one enzyme ( $M s p I)$. The RFLP patterns obtained with enzymes Hae III and MspI are shown in Fig. 1. The variability observed between strain E956 and the clinical isolates was confirmed by sequencing the central region of the E956 flagellin gene. Fig. 2 shows an alignment of the E956 flagellin gene sequence with a 766-bp region of the central area of the flagellin genes from clinical isolates E503 and E505 and the equivalent region of the published flagellin gene

\section{8}

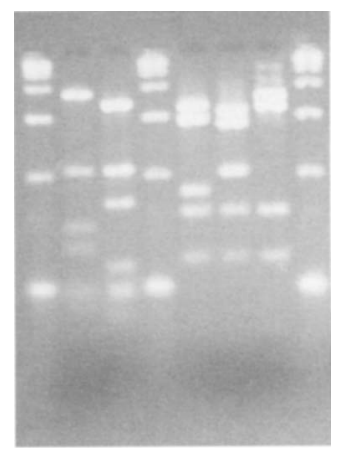

Fig. 1. Agarose gel indicating different flagellin gene PCR/RFLP patterns obtained with the endonucleases HaeIII and MspI. The gel shows flagellin gene amplified products from: lane 2, E955 digested with Hae III; 3, E956 digested with HaeIII; 5, E958 digested with Msp I; 6, E959 digested with Msp I; 7, E960 digested with MspI. PCR size marker is present in lanes 1, 4 and 8 .

sequence from another clinical isolate of $B$. pseudomallei [15]. Over the region shown, the E956 flagellin gene sequence shared an $89.5-89.6 \%$ identity with the flagellin genes of the clinical isolates. A 15-bp deletion was identified in the E956 flagellin gene sequence (position 449-463; Fig. 2).

\section{PFGE genotyping}

PFGE of macrorestricted chromosomal DNA from the four clinical isolates revealed two distinct patterns. Strains E503 and E505 exhibited identical restriction patterns differing in more than four band positions from the pattern found with strains E504 and E506, which were indistinguishable from each other. Of the environmental isolates, E959 and E960 produced unique patterns which were different from each other and all the other isolates. Environmental isolates E955, E956, E957 and E958 produced a pattern differing from that of clinical isolates E503 and E505 by fewer than three bands. Thus they can be considered to be similar isolates of the same strain.

\section{Cable pilus typing by PCR}

PCR amplification with $B$. cepacia cable pilin primers produced no detectable amplicons from any of the $B$. pseudomallei isolates used in this study, whereas the control B. cepacia (ET12) strain produced the expected amplicon of $676 \mathrm{bp}$.

\section{Discussion}

By sequence alignment, it was possible to predict that the location of the small number of variable nucleotides in the flagellin gene sequences of the clinical isolates would lead to substitutions that were synonymous. Thus, despite the geographical variation in the sources of the isolates, there was no evidence of any 


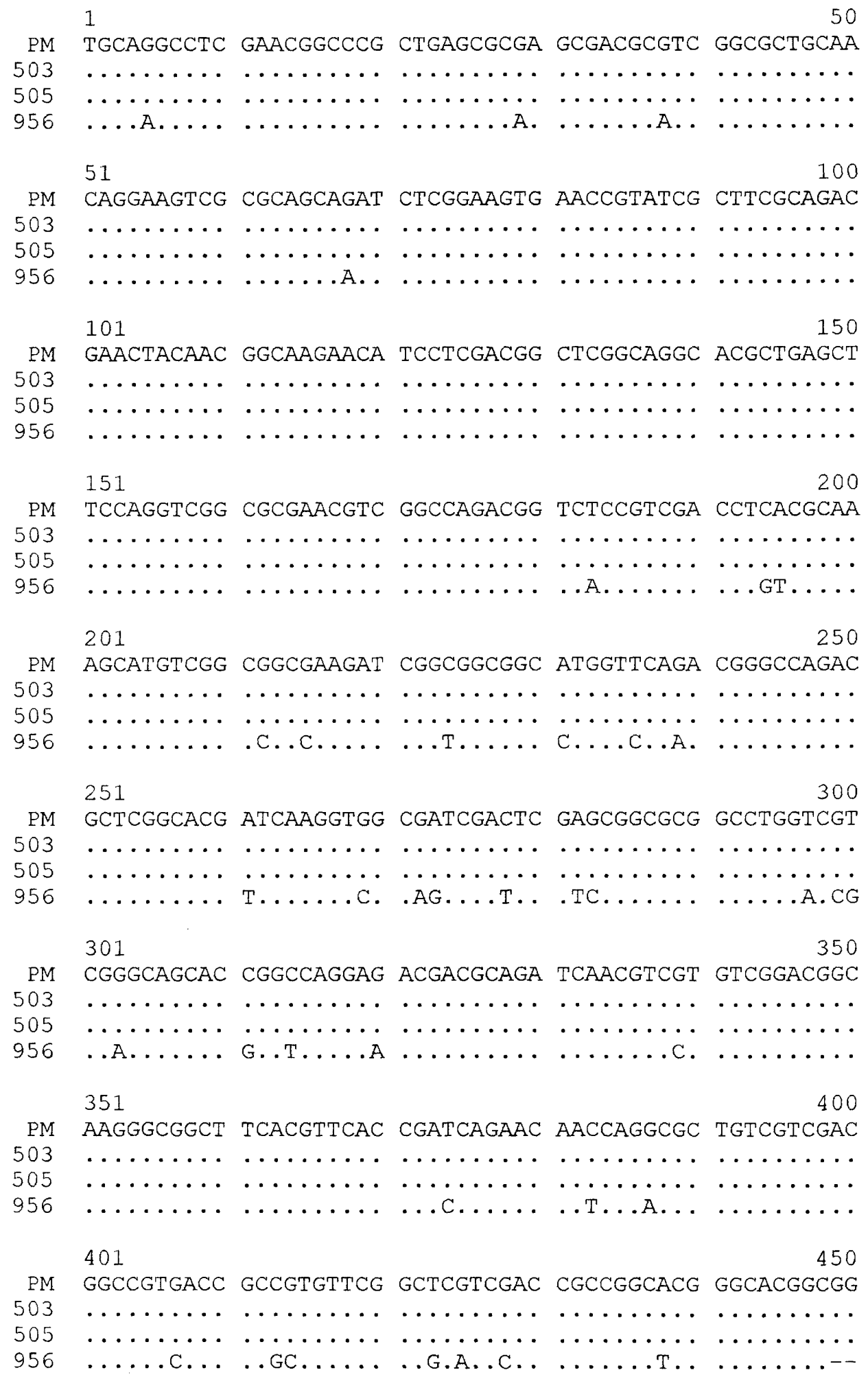

Fig. 2. Alignment of $B$. pseudomallei flagellin gene sequences. PM indicates the previously published sequence of Deshazer et al. [15]. Only bases differing from this sequence are shown for the flagellin genes of E503, E505 and E956. Identical residues are indicated by (.), deletions are indicated by (-).

flagellin protein divergence amongst the clinical isolates of B. pseudomallei.

The flagellin gene sequence invariance observed among the clinical isolates of $B$. pseudomallei has been observed in other pathogenic bacteria [19]. The results support the observations of Brett et al. [20], who isolated flagellin proteins from four strains of $B$. pseudomallei and found them all to have a similar mass of c. $43.4 \mathrm{kDa}$. Flagellin gene sequence invariance, despite the geographical variation in isolate source (Malaysia and Preston/Goa) and the variability often observed in flagellin gene sequences [9], is indicative of a clonal population structure. However, 


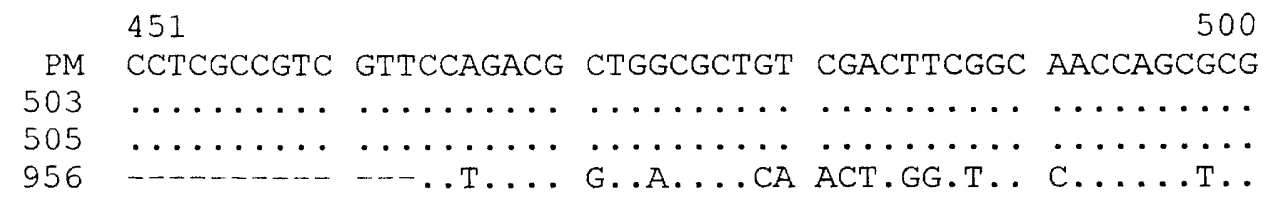

501

550

CTGTCCGCGA CCGACCAGGC GAACGCCACG GCGATGGTTG CGCAGATCAA

PM CGCGGTCAAC AAGCCGCAAA CGGTCTCGAA CCTCGACATC AGCACGCAGA

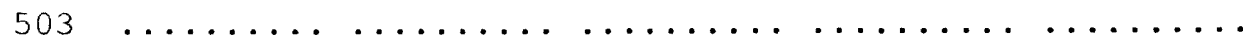

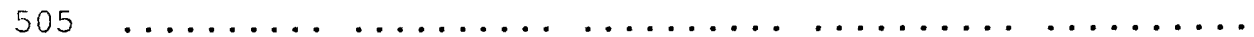

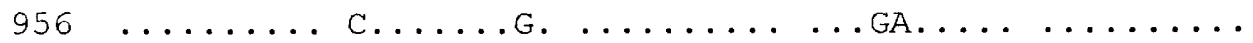

601

PM CGGGCGCGTA CCAGGCGATG GTATCGATCG ACAACGCACT CGCGACGgTC

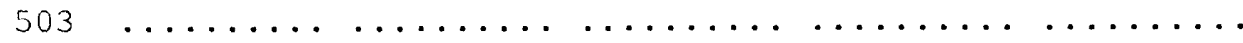

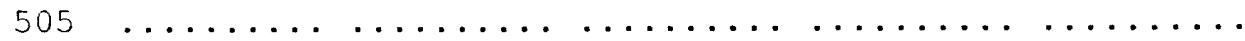

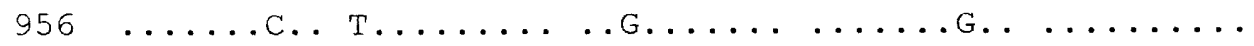

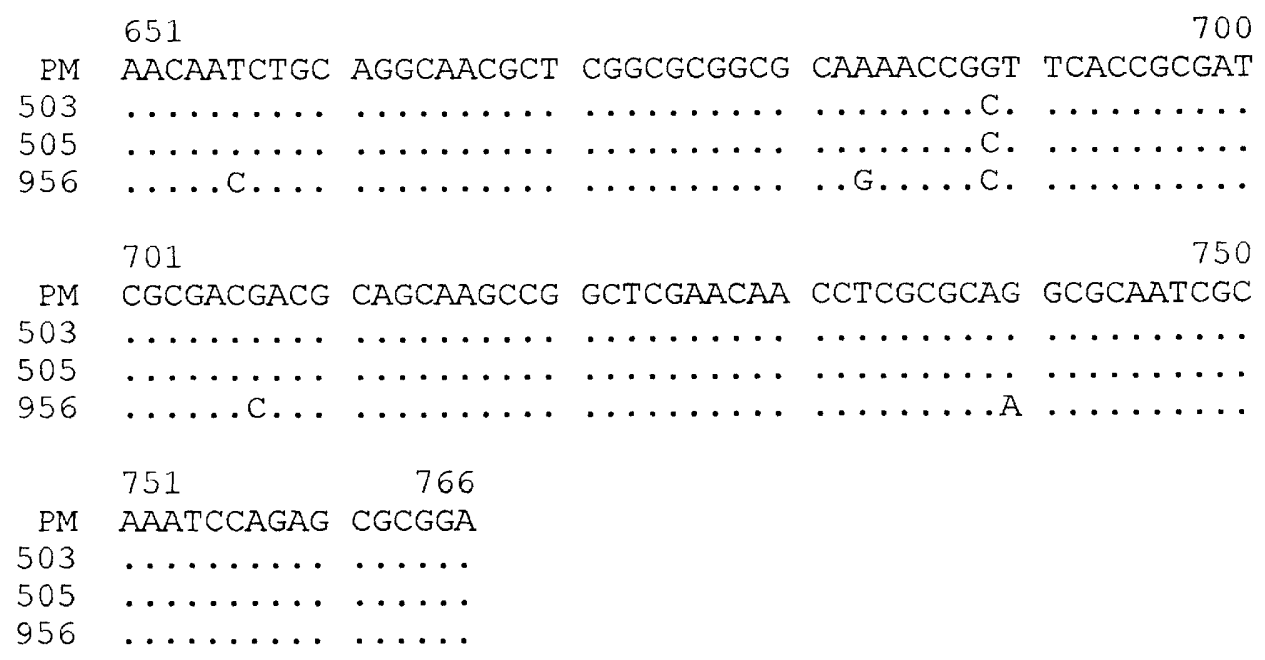

Fig. 2. (continued)

flagellin genotype variation was found between the clinical isolates and some environmental isolates, although three of the six environmental isolates were indistinguishable from clinical isolates by flagellin gene PCR/RFLP and one of the environmental isolates exhibited variation with only one enzyme.

Macrorestriction analysis by PFGE confirmed that clinical isolates E503 and E505, and the environmental isolates E955, E957 and E958 were indistinguishable, suggesting a high degree of clonality in $B$. pseudomallei populations. However, there were differences between the relationships inferred by flagellin genotyping and PFGE. The results suggest that not only can PFGE be used to discriminate between strains of the same flagellin genotype, but flagellin genotyping can be used to distinguish between some strains exhibiting the same PFGE restriction pattern, suggesting that a combination of molecular typing methods may be useful for better discrimination.

The inability to amplify cable pilin genes from $B$. pseudomallei strains suggests either that cable pili are not present or, if present, the cable pilin gene in $B$. pseudomallei is sufficiently different from the $B$. cepacia cable pilin gene to prevent primer annealing.

The pathogenic abilities of the environmental isolates used in this study are unknown, whereas all the clinical isolates were associated with disease. Brett et al. [21] examined a number of clinical and environmental isolates for morphological and biochemical characteristics and for virulence. Having also determined the $16 \mathrm{~S}$ rRNA sequences, the authors suggested that the highly virulent $B$. pseudomallei strains were 
the true $B$. pseudomallei strains and that strains of low virulence could be distinguished from the true strains by significant differences in exoenzyme production, hamster virulence and $16 \mathrm{~S}$ rRNA gene sequences. A study of many more isolates of $B$. pseudomallei will be required to ascertain whether flagellin genotyping can be applied to differentiate between high and low virulence strains of $B$. pseudomallei. However, the method reported here should prove useful for the identification of different clonal variants of the organism, and may provide a way of discriminating between true $B$. pseudomallei strains and $B$. pseudomallei-like strains.

This study was supported by a grant to C.W. from the Wellcome Trust $(044249 / \mathrm{PMG} / \mathrm{VW})$. This work benefited from the use of the SEQNET facility, Daresbury, UK

\section{References}

1. Lew AE, Desmarchelier PM. Molecular typing of Pseudomonas pseudomallei: restriction fragment length polymorphisms of rRNA genes. J Clin Microbiol 1993; 31: 533-539.

2. Currie B, Smith-Vaughan H, Gelledge C, Buller N, Sriprakash $\mathrm{KS}$, Kemp DJ. Pseudomonas pseudomallei isolates collected over 25 years from a non-tropical endemic focus show clonality on the basis of ribotyping. Epidemiol Infect 1994; 113: $307-312$.

3. Sexton MM, Goebel LA, Godfrey AJ, Choawagul W, White NJ, Woods DE. Ribotype analysis of Pseudomonas pseudomalle isolates. J Clin Microbiol 1993; 31: 238-243.

4. Trakulsomboon S, Dance DAB, Smith MD, White NJ, Pitt TL. Ribotype differences between clinical and environmental isolates of Burkholderia pseudomallei. $J$ Med Microbiol 1997; 46: $565-570$

5. Haase A, Smith-Vaughan H, Melder A et al. Subdivision of Burkholderia pseudomallei ribotypes into multiple types by random amplified polymorphic DNA analysis provides new insights into epidemiology. J Clin Microbiol 1995; 33: 1687-1690.

6. Vadivelu J, Puthucheary SD, Mifsud A, Drasar BS, Dance DAB, Pitt TL. Ribotyping and DNA macrorestriction analysis of isolates of Burkholderia pseudomallei from cases of melioidosis in Malaysia. Trans $R$ Soc Trop Med Hyg 1997; 91: $358-360$.

7. Dharakul T, Songsivilai S, Viriyachitra S, Luangwedchakarn V, Tassaneetritap B, Chaowagul W. Detection of Burkholderia pseudomallei DNA in patients with septicemic melioidosis. $J$ Clin Microbiol 1996; 34: 609-614.

8. Lew AE, Desmarchelier PM. Detection of Pseudomonas pseudomallei by PCR and hybridization. $J$ Clin Microbiol 1994; 32: $1326-1332$

9. Winstanley C, Morgan JAW. The bacterial flagellin gene as a biomarker for detection, population genetics and epidemiological analysis. Microbiology 1997; 143: 3071-3084.

10. Alm RA, Guerry P, Trust TJ. Distrubution and polymorphism of the flagellin genes from isolates of Campylobacter coli and Campylobacter jejuni. J Bacteriol 1993; 175: 3051-3057.

11. Kilger G, Grimont PAD. Differentiation of Salmonella phase flagellar antigen types by restriction of the amplified $\mathrm{fiC}$ gene. $J$ Clin Microbiol 1993; 31: 1108-1110.

12. Forbes KJ, Fang Z, Pennington TH. Allelic variation in the Helicobacter pylori flagellin genes flaA and $f a \mathrm{~B}$ : its consequences for strain typing schemes and population structure. Epidemiol Infect 1995; 114: 257-266.

13. Winstanley C, Coulson MA, Wepner B, Morgan JAW, Hart CA. Flagellin gene and protein variation amongst clinical isolates of Pseudomonas aeruginosa. Microbiology 1996; 142: 2145-2151.

14. Hales BA, Morgan JAW, Hart CA, Winstanley C. Variation in flagellin genes and proteins of Burkholderia cepacia. $J$ Bacteriol 1998; 180: 1110-1118.

15. Deshazer D, Brett PJ, Carlyon R, Woods DE. Mutagenesis of Burkholderia pseudomallei with Tn5-OT182: isolation of motility mutants and molecular characterization of the flagellin structural gene. J Bacteriol 1997; 179: 2116-2125.

16. Winstanley C, Carter JP, Seasman M, Morgan JAW, Pickup RW, Saunders JR. A comparison of the survival of stable and unstable chromosomally located $x y l E$ marker cassettes as an indicator of cell division within populations of Pseudomonas putida released into lake water and soil. Microbial Releases 1993; 2: $97-107$

17. Sajjan US, Sun L, Goldstein R, Forstner JF. Cable (Cbl) type II pili of cystic fibrosis-associated Burkholderia (Pseudomonas) cepacia: nucleotide sequence of the cblA major subunit pilin gene and novel morphology of the assembled appendage fibers. $J$ Bacteriol 1995; 177: 1030-1038.

18. Pearson WR, Lipman DJ. Improved tools for biological sequence comparison. Proc Natl Acad Sci USA 1988; 85: 2444-2448.

19. Smith NH, Selander RK. Sequence invariance of the antigencoding central region of the phase 1 flagellar filament gene (fiC) among strains of Salmonella typhimurium. I Bacteriol 1990; 172: 603-609.

20. Brett PJ, Mah, DCW, Woods DE. Isolation and characterization of Pseudomonas pseudomallei flagellin proteins. Infect Immun 1994; 62: 1914-1919.

21. Brett PJ, Deshazer D, Woods DE. Characterization of Burkholderia pseudomallei and Burkholderia pseudomallei-like strains. Epidemiol Infect 1997; 118: 137-148. 